\title{
Article \\ Analysis of the Aggregate Effect on the Compressive Strength of Concrete Using Dune Sand
}

\author{
Euibae Lee ${ }^{1}$, Jeongwon Ko ${ }^{1}$, Jaekang Yoo ${ }^{1}$, Sangjun Park ${ }^{2}$ and Jeongsoo Nam ${ }^{3, *(\mathbb{D}}$ \\ 1 Daewoo Institute of Construction Technology, DAEWOO E\&C, Seoul 04548, Korea; \\ mir2468@naver.com (E.L.); Jeongwon.ko@daewooenc.com (J.K.); jaekangyoo@gmail.com (J.Y.) \\ 2 Department of Building Construction, Korea Polytechnics, Gumi 39257, Korea; concrete@kopo.ac.kr \\ 3 Department of Architectural Engineering, Chungnam National University, Daejeon 34134, Korea \\ * Correspondence: j.nam@cnu.ac.kr; Tel.: +82-42-821-5629
}

check for updates

Citation: Lee, E.; Ko, J.; Yoo, J.; Park, S.; Nam, J. Analysis of the Aggregate Effect on the Compressive Strength of Concrete Using Dune Sand. Appl. Sci. 2021, 11, 1952. https://doi.org/ 10.3390/app11041952

Academic Editor:

Giuseppe Lacidogna

Received: 5 February 2021

Accepted: 19 February 2021

Published: 23 February 2021

Publisher's Note: MDPI stays neutral with regard to jurisdictional claims in published maps and institutional affiliations.

Copyright: (c) 2021 by the authors. Licensee MDPI, Basel, Switzerland. This article is an open access article distributed under the terms and conditions of the Creative Commons Attribution (CC BY) license (https:/ / creativecommons.org/licenses/by/ $4.0 /)$.

\begin{abstract}
In this study, the compressive strengths of concrete were investigated based on water content and aggregate volume fractions, comprising dune sand (DS), crushed sand (CS), and coarse aggregate (CA), for different ages. Experimental data were used to analyze the effects of the volume fraction changes of aggregates on the compressive strength. The compressive strength of concrete increases until the volumetric DS to fine aggregate (FA) ratio (DS/FA ratio) reaches $20 \%$, after which it decreases. The relationship between changes in compressive strength and aggregate volume fractions was analyzed considering the effect factor of each aggregate on the compressive strength and at 2 conditions: (1) $0<\mathrm{DS}<\mathrm{CS}<\mathrm{CA}$ and (2) $0<\mathrm{CA}<\mathrm{CS}<\mathrm{DS}$. For condition (1), when the effect factor of $C A=1$, those of DS and CS were within $0.04-0.83$ and $0.72-0.92$, respectively, for all mixtures. For condition (2), when the effect factor of DS $=1$, those of CS and CA were within $0.68-0.80$ and $0.02-0.79$, respectively.
\end{abstract}

Keywords: dune sand; crushed sand; effect factor; compressive strength; concrete

\section{Introduction}

Among its components, the aggregate accounts for approximately $60-70 \%$ of the total volume of concrete; thus, it has a significant impact on concrete properties. In general, concrete aggregate can be classified as fine aggregate (FA) or coarse aggregate (CA). The workability and mechanical properties of concrete vary depending on the physical properties and mix proportions of the different aggregates. In some regions, three or more types of aggregates are used because of the quality characteristics of the aggregates produced in those regions. As the number of aggregates used in a concrete mix increases, the influences of each aggregate on the properties of the concrete become increasingly complicated. Therefore, to optimize the basic properties of concrete, including workability and strength, significant attention needs to be paid to the proportions of aggregates used in the concrete mix.

In the Middle East and North Africa, crushed sand (CS) and dune sand (DS) have been used as FAs for concrete. However, the CS produced in these regions does not meet the standard particle size requirement for a FA because it is composed of relatively large particles with angular shapes. Unlike CS, DS is composed of relatively small particles with spherical shapes [1]. Due to these properties, if only CS is used for concrete production, the workability of the resulting concrete is considerably low, which makes it quite difficult to perform pumping and compaction when the concrete is used in construction. However, mixing these two types of FAs could effectively improve the workability of concrete because each FA could compensate for the drawbacks of the other.

Zhang et al. [2] performed basic experiments on DS mortar and concrete and reported that $28-32 \%$ was the appropriate proportion of CA in a DS mix to ensure concrete workability. Al-Harthy et al. [3] reported that when DS and CS were used together as FAs, the 
slump of the resulting concrete increased until a DS replacement ratio of $50 \%$ was attained; thereafter, the slump decreased as the DS replacement ratio increased. Bouziani et al. [4] conducted research on high-flow sand concrete composed of DS and river sand (RS). They reported that the fluidity of the resulting concrete improved by up to $10 \%$ when DS (with a fineness modulus, $F M=1)$ was replaced by RS (FM = 3.03), wherein the RS particles met the standard particle size requirement for a FA. Seif and Sedek [5] examined the differences in the basic properties of mortar based on different mix proportions of DS and CS sourced from four regions of Egypt, and found that the slump increased as the DS replacement ratio increased up to $70 \%$. Belhadj et al. [6] studied the mechanical properties of sand concrete composed of RS, DS, CS, or RDS (i.e., RS + DS, 1.7:1) and observed that the performance of the concrete could be improved by improving the particle size distribution through the addition of DS.

As discussed above, although improvements in the workability of concrete have been reported when a certain proportion of a FA with a large FM, such as CS, is added with DS, different results have been obtained in terms of the compressive strength properties of the resulting concrete. Al-Harthy et al. [3] reported that the compressive strength of concrete decreased as the DS replacement ratio increased. Khay et al. [7] examined the properties of sand concrete composed of DS and CS and reported that the compressive and flexural strengths of this sand concrete were lower than those of sand concrete composed of only CS. Seif and Sedek [5] observed that the compressive strength of sand concrete slowly decreased as the DS replacement ratio increased up to $70 \%$; however, it rapidly decreased thereafter. In contrast, Rmili et al. [8] reported that the compressive strength of concrete increased until a DS replacement ratio of $15 \%$ was attained; however, it slowly decreased thereafter. In addition, Bouziani et al. [4] reported that the compressive strength of concrete improved until the DS replacement ratio increased to $10 \%$. Luo et al. [9] reported that the compressive strength increased until the DS replacement ratio attained a certain value, but it decreased at higher replacement ratios. Thus, some studies have reported that the compressive strength of concrete decreased as the DS replacement ratio increased, whereas others have suggested that the maximum compressive strength of concrete is realized at a specific DS replacement ratio.

In general, the properties of an aggregate that affect the strength of concrete include the strength, shape, surface texture, maximum size, and particle size of the aggregate [10]. Although the DS used in previous studies had similar shapes and surface textures [1], the strength of the DS or properties of other aggregates that were used with the DS in the concrete mix differed among the studies; thus, the effect of DS on the compressive strength of concrete may have varied among the studies. Hence, further experimental studies under various conditions are required for a comprehensive quantitative analysis of the properties of DS and other aggregates, as well as the properties of DS combined with other aggregates, which affect the compressive strength of concrete.

In this study, concrete was produced using CS and DS from the Middle East region, and the effects of these aggregates on the strength of concrete were examined. To this end, the compressive strength properties of concrete for different unit water contents and volumetric DS to FA ratios (DS-FA ratio) were investigated for different ages. In addition, the effect of volume changes of each aggregate on the compressive strength properties of concrete were quantitatively analyzed based on the measured compressive strength at each age.

\section{Experimental Plan and Method}

\subsection{Experimental Plan}

Considering the concrete mixture conditions, the water-cement ratio and target slump were set to 0.4 and $180 \pm 25 \mathrm{~mm}$, respectively. Furthermore, different water contents and DS/FA ratios were considered in the concrete mix, i.e., the amounts of these components in the concrete mixture were varied. The following values were set for each condition: Water contents $=170,160$, and $150 \mathrm{~kg} / \mathrm{m}^{3} ;$ DS $/$ FA ratios $=10,20,40$, and $60 \%$. 
The basic properties of fresh concrete, including its slump and air content, were measured immediately after mixing. Each property was tested in accordance with the relevant standard: KS F 2402 [11] (ASTM C 143 [12]) and KS F 2421 [13] (ASTM C 231 [14]) for slump and air content. In addition, the compressive strength of concrete was measured at 3, 7, 14, and 28 day ages in accordance with the KS F 2405 standard [15] (ASTM C 39 [16]).

\subsection{Materials and Mixture Proportions}

To conduct concrete experiment, DS and CS, which were core materials for the research purpose, were imported from the Middle East. Other concrete materials were produced in Korea.

Table 1 lists the materials used in this study, along with their physical properties. In this study, limestone-based CS and coarse aggregate were used, and the main chemical components of DS is shown in Table 2.

Table 1. Materials used in this study and their physical properties.

\begin{tabular}{|c|c|}
\hline Material & Physical Properties \\
\hline Cement & $\begin{array}{l}\text { - Ordinary Portland cement (OPC) } \\
\text { - Density: } 3.15 \mathrm{~g} / \mathrm{cm}^{3} \\
\text { - Fineness: } 3440 \mathrm{~cm}^{2} / \mathrm{g}\end{array}$ \\
\hline CA & $\begin{array}{l}\text { - Coarse aggregate } \\
\text { - Maximum size: } 20 \mathrm{~mm} \\
\text { - Density: } 2.70 \mathrm{~g} / \mathrm{cm}^{3} \\
\text { - Absorption ratio: } 0.77 \%\end{array}$ \\
\hline CS & $\begin{array}{l}\text { - Maximum size: } 5 \mathrm{~mm} \\
\text { - Density: } 2.61 \mathrm{~g} / \mathrm{cm}^{3} \\
\text { - FM: } 3.6 \\
\text { - Absorption ratio: } 1.53 \%\end{array}$ \\
\hline DS & $\begin{array}{l}\text { - Density: } 2.61 \mathrm{~g} / \mathrm{cm}^{3} \\
\text { - FM: } 0.7 \\
\text { - Absorption ratio: } 1.19 \%\end{array}$ \\
\hline Admixture & $\begin{array}{l}\text { - Naphthalene based } \\
\text { - Density: } 1.23 \mathrm{~g} / \mathrm{cm}^{3} \\
\text { - pH: } 6.79\end{array}$ \\
\hline
\end{tabular}

Table 2. Chemical composition of DS.

\begin{tabular}{ccccccc}
\hline Chemical & $\mathrm{SiO}_{2}$ & $\mathrm{CaO}$ & $\mathrm{Al}_{\mathbf{2}} \mathbf{O}_{3}$ & $\mathbf{M g O}$ & $\mathrm{Fe}_{\mathbf{2}} \mathrm{O}_{3}$ & $\mathrm{~K}_{\mathbf{2}} \mathbf{O}$ \\
\hline$\%$ & 47.1 & 38.8 & 5.65 & 3.03 & 2.68 & 1.44 \\
\hline
\end{tabular}

Figure 1 shows the particle-size distribution curves for CS, DS, and binary sands with different DS replacement ratios. Figure 1 shows that CS and DS could not meet the standard particle size distribution for FA defined in the KS F 2526 standard [17] (ASTM C 33 [18]). Furthermore, binary sand could not meet the standard particle size distribution; however, its particle size distribution was close to that defined in the standard. Moreover, the fineness modulus (FM) values for CS and DS, which were 3.6 and 0.7 , respectively, are not within the standard FM range of 2.3-3.1 as defined in the KS 2526 standard [17] (ASTM C 33 [18]). In contrast, the FMs of binary sand with 20 and $40 \%$ DS replacement ratios were 3.02 and 2.44, respectively, which are within the standard FM range. 


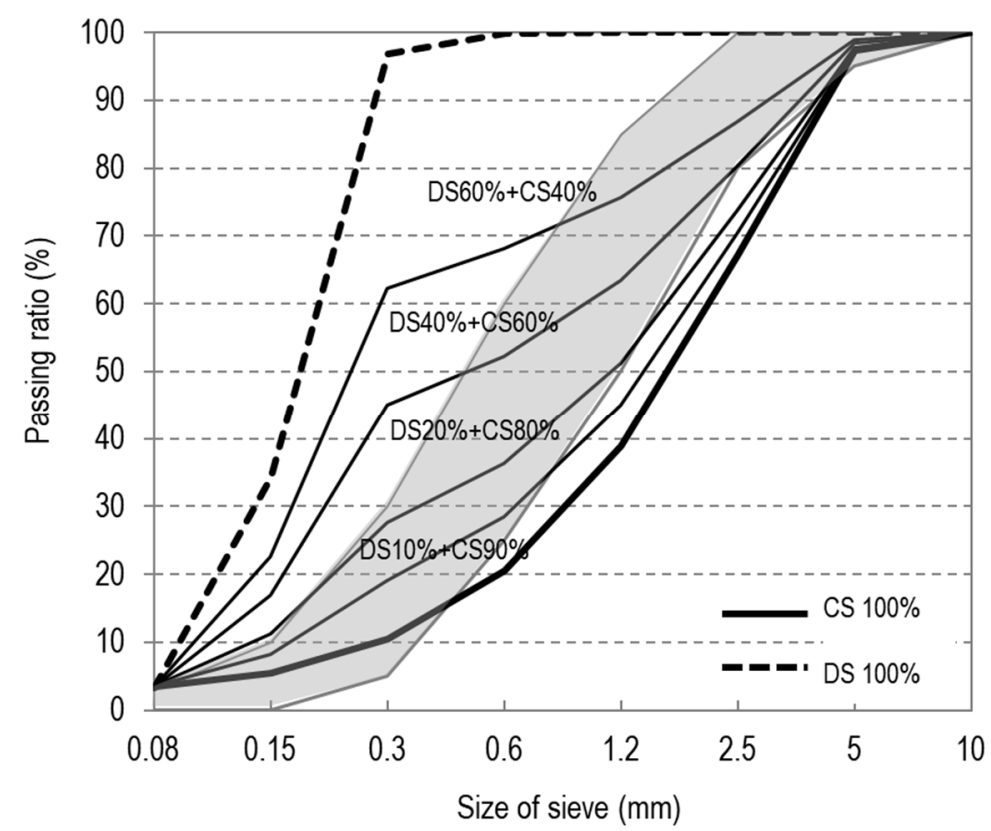

Figure 1. Particle-size distributions of the FAs used in this study.

Table 3 lists the proportions of the different concrete mixtures used in this study. For the experiments, the sand-to-aggregate (s/a) ratio and the chemical admixture (AD) content were set as per the target slump. During experimental mixing, an attempt was made to obtain a concrete mixture using only CS; however, the target slump could not be attained, even though the s-a ratio and AD content were increased. Nevertheless, when at least $10 \%$ DS was substituted instead of CS, it was possible to derive concrete mixtures that met the target slump. In addition, even in the case of binary sand with a 10\% DS/FA ratio, the target slump could not be met when the water content of the concrete mixture was less than $150 \mathrm{~kg} / \mathrm{m}^{3}$. In contrast, when binary sand with a 20\% DS/FA ratio was used, the target slump could be attained with a water content of $150 \mathrm{~kg} / \mathrm{m}^{3}$ in the concrete mixture.

Table 3. Proportions for the different concrete mixtures used in this study.

\begin{tabular}{|c|c|c|c|c|c|c|c|c|c|c|}
\hline \multirow{2}{*}{\multicolumn{2}{|c|}{ Mixture $^{a}$}} & \multirow{2}{*}{$\underset{(\mathrm{mm})}{\text { Slump }}$} & \multirow{2}{*}{ W/C } & \multirow{2}{*}{ s/a } & \multicolumn{5}{|c|}{ Unit Weight $\left(\mathrm{kg} / \mathrm{m}^{3}\right)$} & \multirow{2}{*}{$\underset{(\mathrm{cw} \%)}{\mathrm{AD}}$} \\
\hline & & & & & $w^{b}$ & $\mathrm{C}^{\mathrm{c}}$ & CS & DS & CA & \\
\hline \multirow{4}{*}{ W170 } & DS10 & \multirow{11}{*}{$\begin{array}{c}180 \\
\pm 25\end{array}$} & \multirow{11}{*}{0.4} & 0.60 & 170 & 425 & 951 & 106 & 729 & 0.8 \\
\hline & DS20 & & & 0.50 & 170 & 425 & 705 & 176 & 911 & 0.8 \\
\hline & DS40 & & & 0.45 & 170 & 425 & 476 & 317 & 1002 & 0.7 \\
\hline & DS60 & & & 0.40 & 170 & 425 & 282 & 423 & 1094 & 0.8 \\
\hline \multirow{4}{*}{ W160 } & DS10 & & & 0.65 & 160 & 400 & 1058 & 118 & 655 & 1.0 \\
\hline & DS20 & & & 0.55 & 160 & 400 & 796 & 199 & 842 & 1.0 \\
\hline & DS40 & & & 0.45 & 160 & 400 & 488 & 326 & 1029 & 1.0 \\
\hline & DS60 & & & 0.42 & 160 & 400 & 304 & 456 & 1085 & 1.1 \\
\hline \multirow{3}{*}{ W150 } & DS20 & & & 0.60 & 150 & 375 & 891 & 223 & 768 & 1.2 \\
\hline & DS40 & & & 0.48 & 150 & 375 & 534 & 356 & 998 & 1.5 \\
\hline & DS60 & & & 0.43 & 150 & 375 & 319 & 479 & 1094 & 1.3 \\
\hline
\end{tabular}

${ }^{\mathrm{a}} \mathrm{W} 170=$ Water content $170 \mathrm{~kg} / \mathrm{m}^{3}$, DS10 $=$ DS/FA ratio $10 \% .{ }^{\mathrm{b}} \mathrm{W}$ : Water. ${ }^{\mathrm{c}} \mathrm{C}$ : Cement.

\section{Results and Discussion}

\subsection{Slump}

Figure 2 shows the measured slump of each concrete mixture used in the study, and Figure 3 shows the AD contents that were used to attain the target slump. For the same water content, the change in AD content due to an increase in the DS replacement ratio was small. In contrast, for a constant DS replacement ratio, the AD content required to attain the required slump increased as the water content decreased. In particular, when the water 
content in the concrete mixture decreased from 170 to $160 \mathrm{~kg} / \mathrm{m}^{3}$, the required AD content increased by $25-43 \%$; whereas, when the water content decreased from 160 to $150 \mathrm{~kg} / \mathrm{m}^{3}$, the AD content increased by $18-20 \%$.

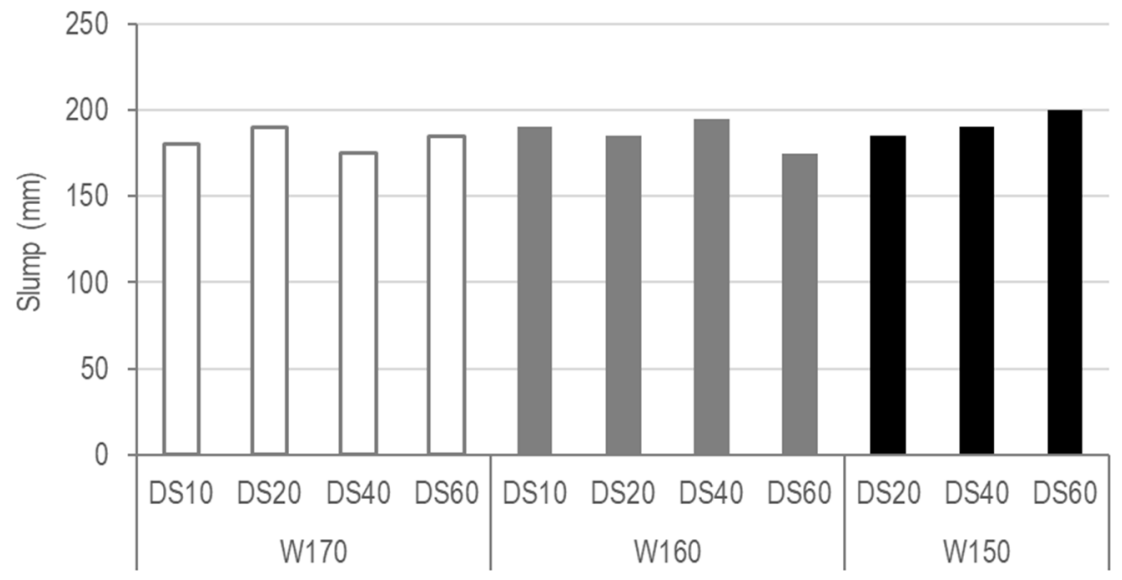

Figure 2. Particle-size distributions of the FAs used in this study.

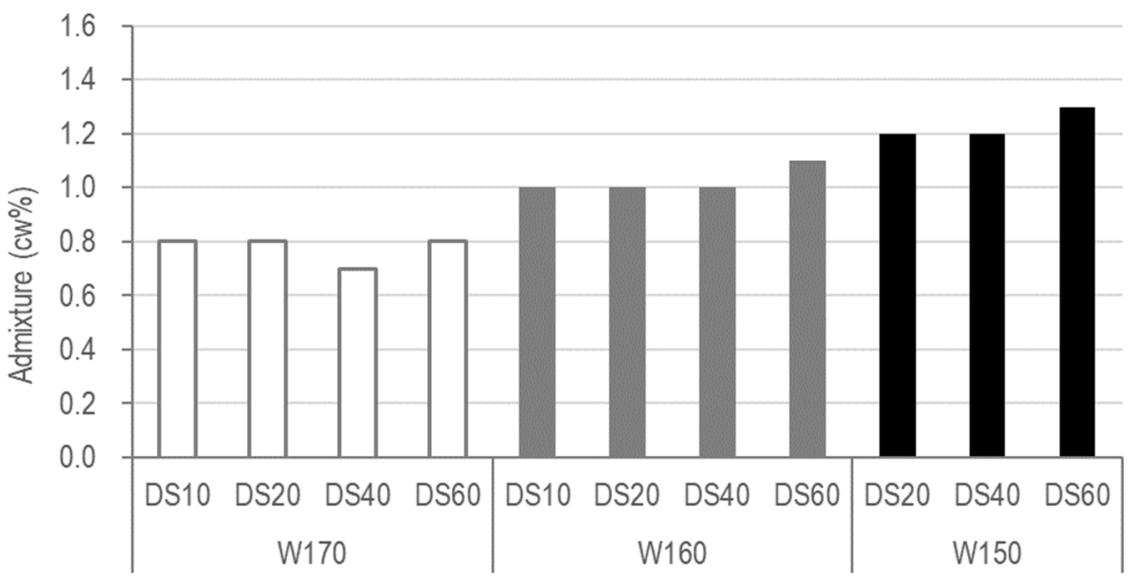

Figure 3. Admixture (AD) contents of the concrete mixtures used to attain the target slump.

For constant water-cement ratios and water contents, all of the mixtures had the same cement paste and aggregate contents. Nevertheless, while the total aggregate volume remained the same, the volume of each aggregate type was different, which affected the workability of the resulting concrete [10]. This indicates that the fluidity improvement effect of an AD may vary depending on the volume fraction of the aggregate, even though the same AD content was used.

In this study, the slump values per unit $\mathrm{AD}$ content (slump to AD ratio, slump/AD ratio) of all the concrete mixtures were calculated and compared. Based on our observations, we determined that high slump/AD ratios can maximize the fluidity improvement effect of the $\mathrm{AD}$ in a concrete mix, indicating that such conditions are favorable for improving the workability of the concrete. Figure 4 shows the slump/AD ratio results for the different concrete mixtures used in this study. 


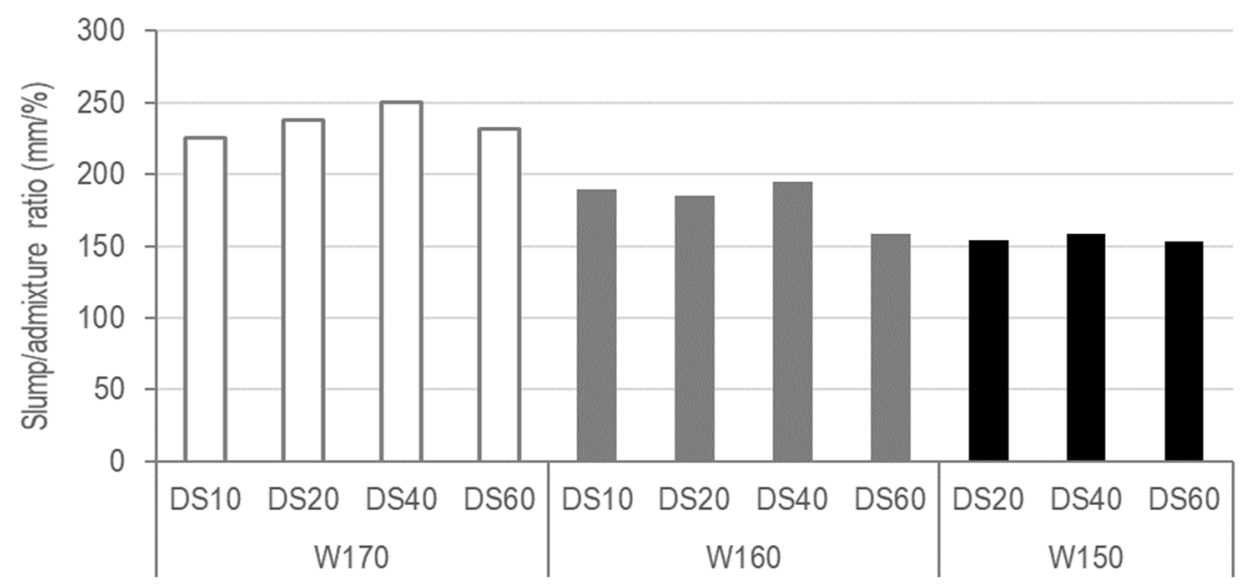

Figure 4. Slump/AD ratios calculated for the different concrete mixtures used in this study.

Among the W170 mixtures, the DS10 mixture had the smallest slump/AD value of $225 \mathrm{~mm} / \%$. Furthermore, the slump/AD ratio increased as the DS/FA ratio increased to $40 \%$ (i.e., DS40); however, it decreased for DS60. The highest slump/AD ratio $(250 \mathrm{~mm} / \%)$ was obtained for the DS40 mixture, which was approximately $11 \%$ higher than that of the DS10 mixture.

Among the W160 mixtures, the lowest slump/AD ratio was $159 \mathrm{~mm} / \%$ for the DS60 mixture, whereas the highest slump/AD ratio $(195 \mathrm{~mm} / \%)$ was observed in the case of the DS40 mixture, which was approximately $23 \%$ higher than that of the DS60 mixture.

Furthermore, among the W150 mixtures, the highest slump/AD ratio $(158 \mathrm{~mm} / \%)$ was observed in the case of the DS40 mixture. A regression analysis was conducted to identify the DS/FA ratio that exhibited the highest slump/AD ratio. We found that the optimal DS/FA ratios for the W170, W160, and W150 mixtures were 37, 27, and 40\%, respectively.

\subsection{Air Contents}

Figure 5 shows the air contents of the different concrete mixtures used in this study. For all mixtures, the air content ranged between 0.4 and $1.3 \%$. It should be noted that no significant correlations were observed between a change in air content and those of water content or DS/FA ratio.

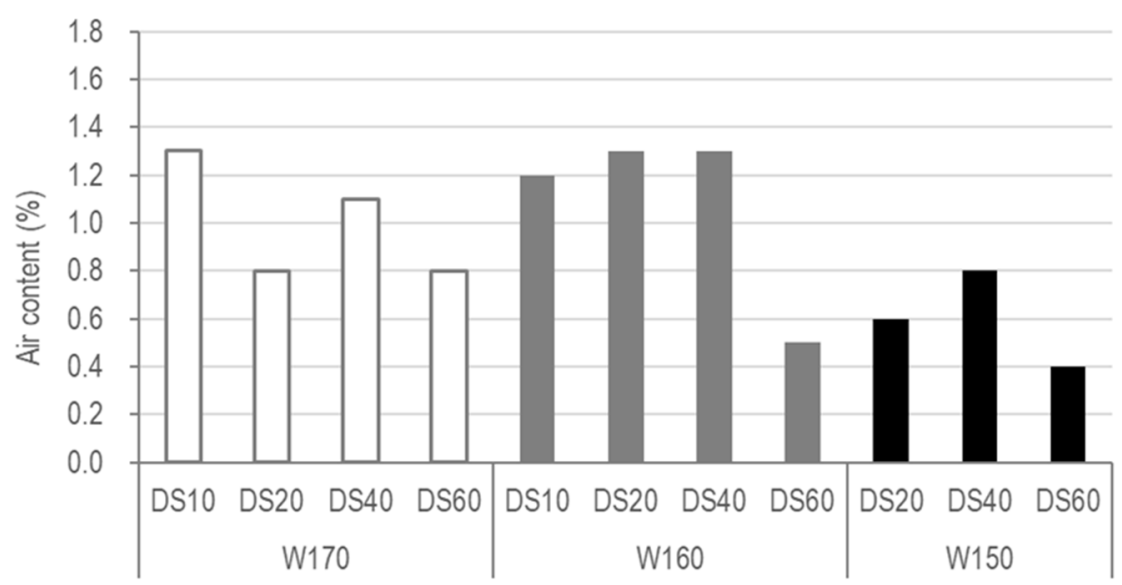

Figure 5. Air contents of the different concrete mixtures used in this study.

It has been reported that FA with particle sizes of $0.15-0.06 \mathrm{~mm}$ lead to a higher air content in the concrete mixture than those with larger particle sizes; while, FAs with particle sizes less than $0.15 \mathrm{~mm}$ lead to a decrease in air content [19]. Among the DS in this study, particles with a size of $0.15-0.06 \mathrm{~mm}$ were approximately $65 \%$ by weight, whereas those 
with a size of less than $0.15 \mathrm{~mm}$ accounted for approximately $35 \%$. Therefore, as the DS/FA ratio increased, the air content could be expected to increase because the amount of FA with particle sizes of $0.15-0.06 \mathrm{~mm}$ increased. However, the experimental result of air content did not show the tendency. This result may be due to the difference between DS and fine aggregates used in previous studies. Particularly, due to differences in physical properties such as particle shape, surface texture, etc., the effect of DS particles on the air content may be different. In addition, the magnitude of the influence of the unit weight of fine aggregates with a specific size range on the increase or decrease in the air content may be different. Therefore, even if the weight of the particles increasing air content increases more than the weight of the particles reducing air content, the air content may not increase. For a more accurate analysis of the DS particle size effect on air content additional experimental studies are needed.

\subsection{Compressive Strength}

Figure 6 shows the compressive strength measurements according to age. Figure 7 shows the mean compressive strengths and standard deviations of the concrete mixtures with different DS/FA ratios. Overall, the compressive strength increased as the DS/FA ratio increased to $20 \%$. This can be attributed to the high compaction effect of the aggregates [9]. Furthermore, the compressive strength decreased when the DS/FA ratio exceeded $20 \%$, which can be attributed to the decrease in bond strength between the cement paste and DS due to the round and smooth surfaces of the DS particles [19]. In addition, the bond strength reduction effect increased with an increase in the amount of DS used.

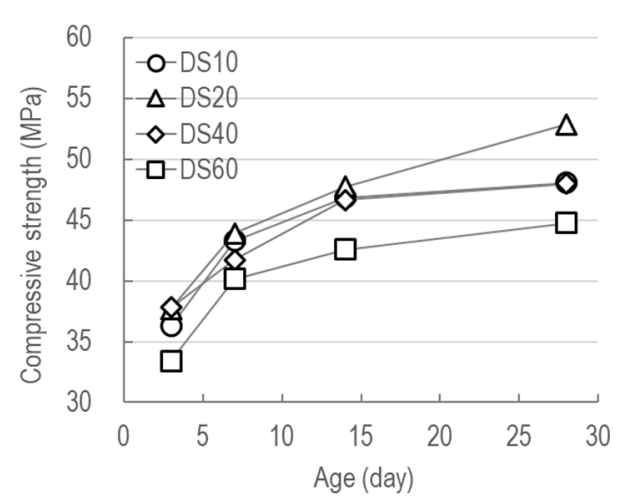

(a)

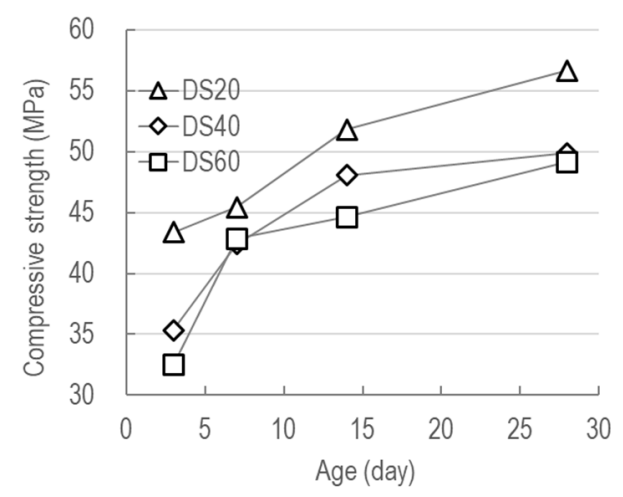

(c)

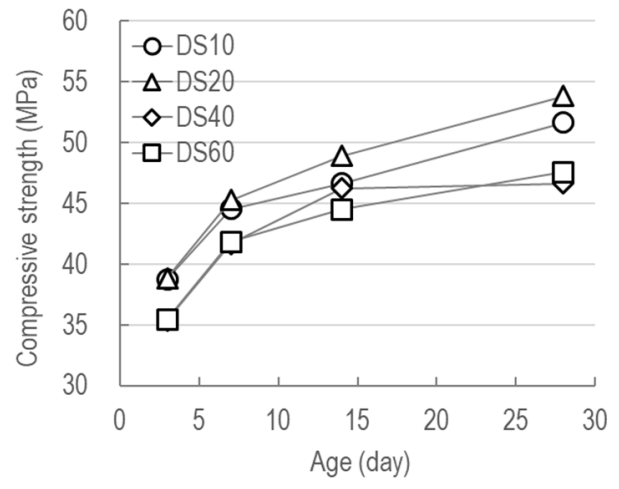

(b)

Figure 6. Compressive strengths of the different concrete mixtures according to age; (a) W170, (b) W160, and (c) W150. 


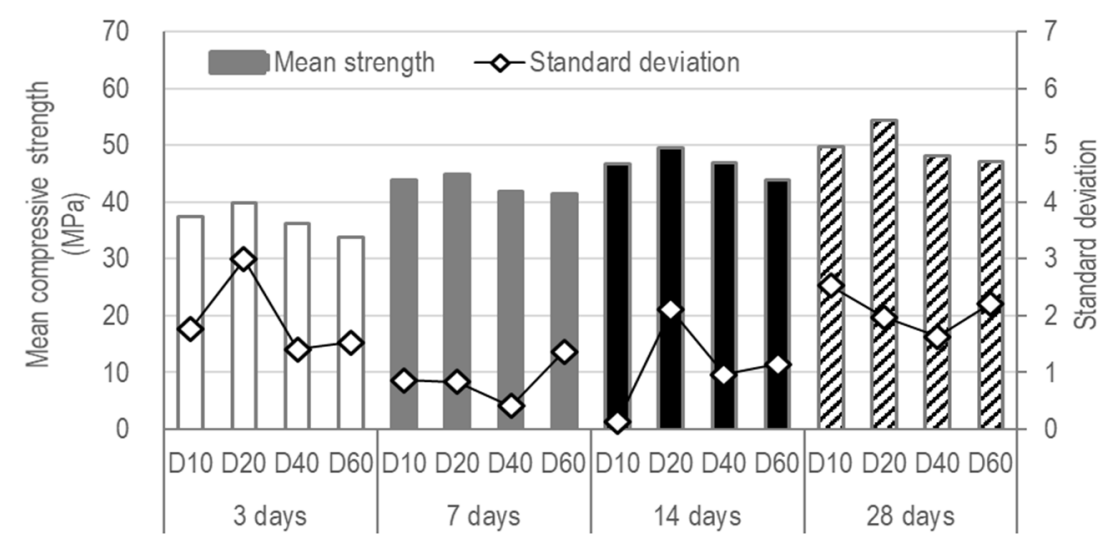

Figure 7. Mean compressive strengths and standard deviations of concrete mixtures with different DS/FA ratios.

Figure 8 shows the mean compressive strengths and standard deviations of concrete mixtures by unit water content. The compressive strength slightly increased when the unit water content decreased, although the water-cement ratio was same. The lower unit water content can lead to lower porosity in the hardened concrete, and can also lead to a higher compressive strength of concrete.

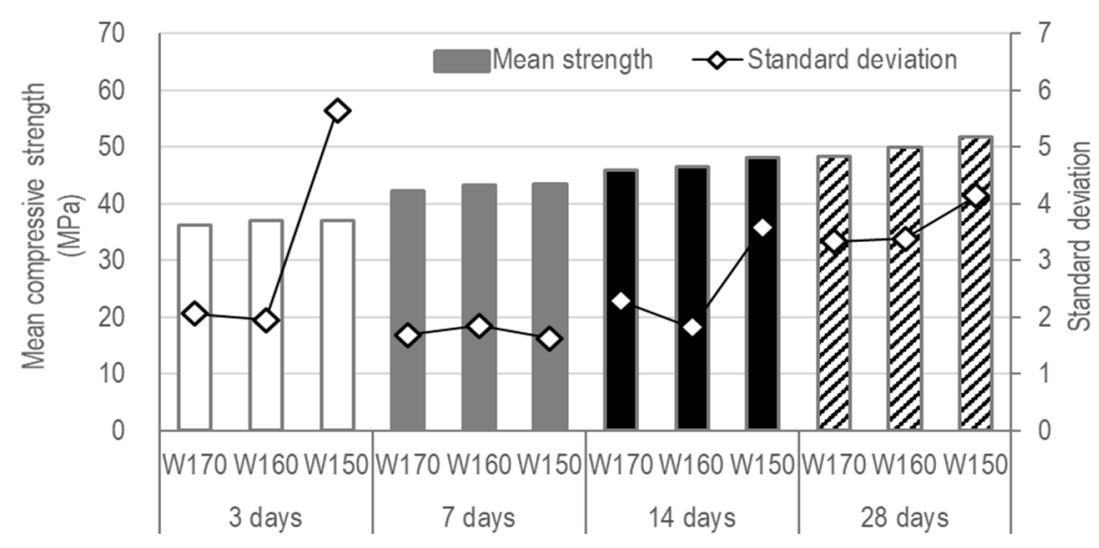

Figure 8. Mean compressive strengths and standard deviations of concrete mixtures with different water contents.

The standard deviations in Figure 7 can be interpreted as the variations in the results by their unit water contents. The standard deviations in Figure 8 can be interpreted as the variations in the results by their DS/FA ratios. A comparison of the results shows that the standard deviations in Figure 8 are larger than those in Figure 7, indicating that the effect of the DS/FA ratio on compressive strength may be greater than the effect of the unit water content on compressive strength. Therefore, in terms of concrete strength using DS and CS, we recommend that the DS/FA ratio should be considered more important than the unit water content in the mixture.

\subsection{Aggregate Effect on Compressive Strength}

As specified above, mixtures with the same water-cement ratios and water contents had the same paste and aggregate volumes. However, there were differences in aggregate volume fractions for the different DS replacement ratios. Figure 9 shows the aggregate volume fractions and compressive strengths by age for each mixture with different water contents and DS/FA ratios. Because the mixtures with the same paste and aggregate volumes also had different compressive strengths depending on their aggregate volume fractions, we deduced that the aggregate volume fraction has an impact on the compressive strength of concrete. 


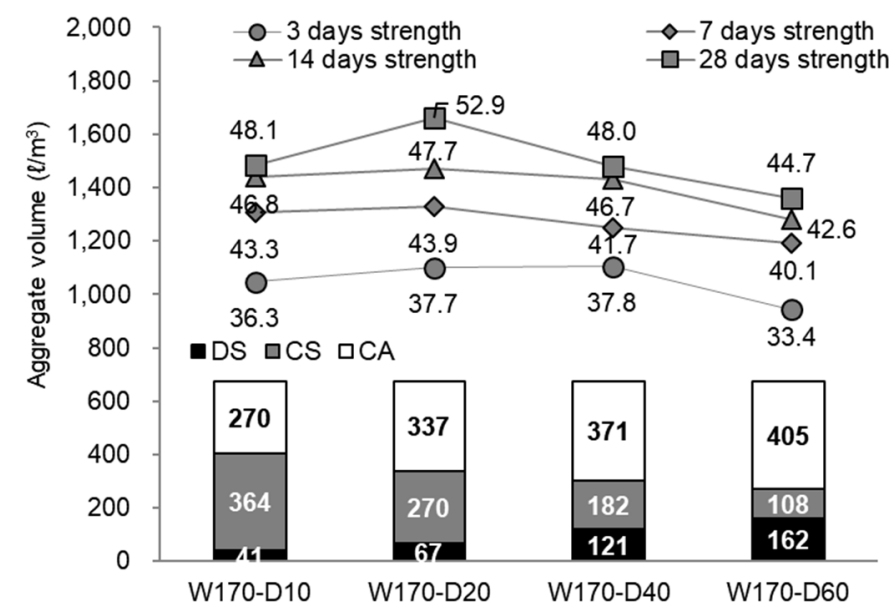

(a)

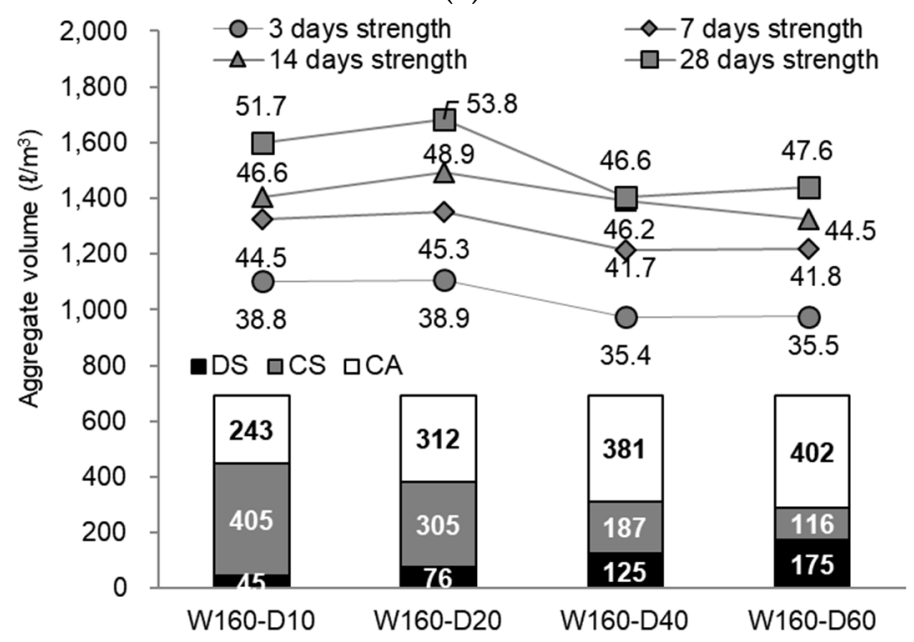

(b)

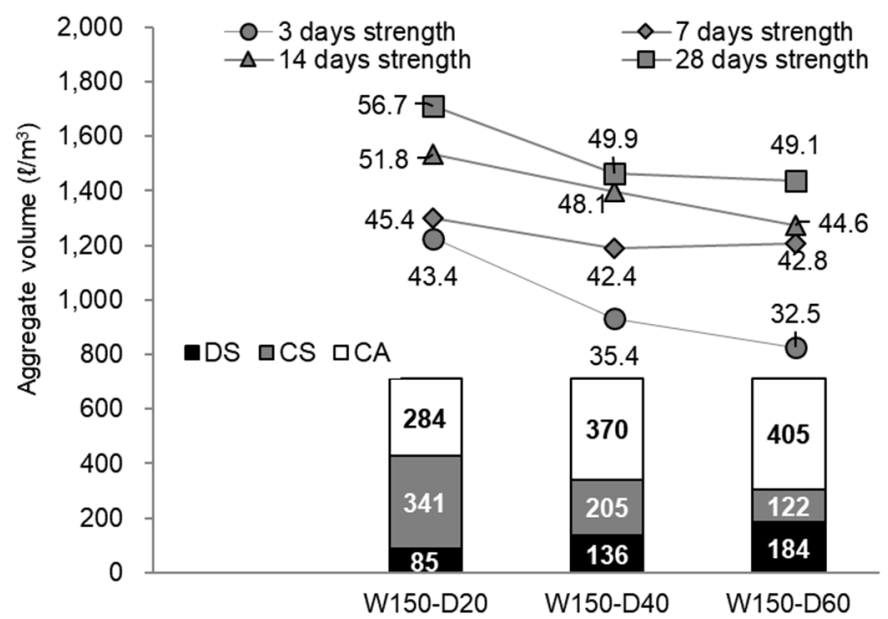

(c)

Figure 9. Aggregate volume fractions and compressive strengths of (a) W170, (b) W160, and (c) W150.

In this study, to analyze the effect of aggregates on the compressive strength of concrete, the following equation was proposed that considers the change in the compressive strength of each mixture, the change in aggregate volume fractions, and the effect factors of each aggregate type on the compressive strength. In this study, the effect factor was used as a coefficient representing the properties of the aggregate that could affect the compressive 
strength of the concrete. In addition, although the relationship between the compressive strength of concrete and the aggregate properties may be expressed as a polynomial, a monomial expression was first adopted in this study.

$$
\Delta S=a \cdot \Delta D S+b \cdot \Delta C S+c \cdot \Delta C A
$$

where $\Delta S$ is the change in compressive strength (Mpa), $\triangle D S$ is the change in $D S$ volume $(\ell), \triangle C S$ is the change in $C S$ volume $(\ell), \triangle C A$ is the change in $C A$ volume $(\ell), a$ is the effect factor of $D S$ on compressive strength (Mpa/ $\ell$ ), $b$ is the effect factor of $C S$ on compressive strength $(\mathrm{Mpa} / \ell)$, and $c$ is the effect factor of $\mathrm{CA}$ on compressive strength $(\mathrm{Mpa} / \ell)$.

First, the changes in compressive strength and aggregate volume fractions were calculated for the mixtures that exhibited the highest compressive strength at each age among the mixtures with the same water contents. Among the W170 mixtures, the W170D40 mixture was used as the reference mixture only for the W170-D20 mixture at an age of 3 days, whereas the W170-D20 mixture was used as the reference for the other ages. Among the W160 and W150 mixtures, the W160-D20 and W150-D20 mixtures were used as the reference mixtures. Table 3 lists the calculated changes in compressive strength and aggregate volume fractions of the mixtures with respect to the reference mixtures.

Next, the influences of the magnitude of the effect factor of each aggregate type on the changes in the compressive strength of the concrete mixtures were examined. It has been reported that the compressive strength of concrete increases as the particle size of the CA increases [20-25]. On the contrary, some studies have reported that the compressive strength of concrete increases as the particle size of the CA decreases [26-30]. Thus, it is difficult to assess the magnitude of the effect factor of each aggregate type on the concrete compressive strength based on the particle size of the aggregate. In addition to the aggregate particle size, other properties of an aggregate that could affect the compressive strength of concrete include its surface texture, particle shapes, and strength. These properties may indirectly affect compressive strength because they affect the water content, which then affects the workability of the concrete. In contrast, these properties may also directly affect the compressive strength of concrete because they affect the adhesion between the aggregate and the cement paste, stress concentrations during loading, and microcrack patterns [10]. Thus, in this study, the magnitudes of the effect factors of each aggregate type on the compressive strength of concrete were calculated by assuming six cases: Case 1: $0<c<b<$ $a$; Case 2: $0<b<c<a$; Case 3: $0<c<a<b$; Case 4: $0<a<c<b$; Case 5: $0<b<a<c$; and Case 6: $0<a<b<c$.

For each of the cases used to assess the effect factors of each aggregate type, the largest factor value was set to 1 , whereas the second largest factor value was between 0.01 and 0.99 . These values were substituted into Equation (1) to calculate the ranges of the factors that met each assumption. As a result of analyses, we found that only Cases 1 and 6 could meet the assumption when the appropriate values were substituted into Equation (1).

\subsubsection{For $0<a<b<c$ and $c=1$}

Table 4 list the results, with the maximum and minimum values of the effect factors a and $\mathrm{b}$ that satisfy Equation (1) under the conditions: $0<a<b<c$ and $c=1$. In addition, Figure 10 shows the common ranges of the effect factors of DS and CS for each age.

The results indicate that the value of $a$ generally increased as the value of $b$ increased. Similarly, the value of $a$ decreased as the value of $b$ decreased; however, the decrease in $a$ was larger than that of $b$. 
Table 4. Results of the calculated aggregate effect factors $(a<b<c, c=1)$.

\begin{tabular}{|c|c|c|c|c|c|c|c|c|c|c|c|c|c|c|c|c|c|}
\hline \multirow{3}{*}{ Age } & \multirow{3}{*}{$\begin{array}{c}\text { Mixture } \\
\text { Factor }\end{array}$} & \multicolumn{6}{|c|}{ W170 } & \multicolumn{6}{|c|}{ W160 } & \multicolumn{4}{|c|}{ W150 } \\
\hline & & \multicolumn{2}{|c|}{ D10 } & \multicolumn{2}{|c|}{ D40 } & \multicolumn{2}{|c|}{ D60 } & \multicolumn{2}{|c|}{ D10 } & \multicolumn{2}{|c|}{ D40 } & \multicolumn{2}{|c|}{ D60 } & \multicolumn{2}{|c|}{ D40 } & \multicolumn{2}{|c|}{ D60 } \\
\hline & & $a$ & $b$ & $a$ & $b$ & $a$ & $b$ & $a$ & $b$ & $A$ & $b$ & $a$ & $b$ & $a$ & $b$ & $a$ & $b$ \\
\hline \multirow{2}{*}{$\begin{array}{c}3 \\
\text { days }\end{array}$} & Max. & 0.97 & 0.98 & 0.97 & 0.98 & 0.86 & 0.99 & 0.90 & 0.92 & 0.88 & 0.99 & 0.90 & 0.99 & 0.83 & 0.99 & 0.87 & 0.99 \\
\hline & Min. & 0.01 & 0.55 & 0.01 & 0.39 & 0.02 & 0.53 & 0.02 & 0.65 & 0.03 & 0.64 & 0.02 & 0.53 & 0.02 & 0.69 & 0.02 & 0.61 \\
\hline \multirow{2}{*}{$\begin{array}{c}7 \\
\text { days }\end{array}$} & Max. & 0.95 & 0.98 & 0.94 & 0.99 & 0.94 & 0.99 & 0.96 & 0.98 & 0.90 & 0.99 & 0.95 & 0.99 & 0.93 & 0.99 & 0.95 & 0.99 \\
\hline & Min. & 0.04 & 0.72 & 0.02 & 0.42 & 0.01 & 0.45 & 0.02 & 0.69 & 0.01 & 0.62 & 0.01 & 0.50 & 0.01 & 0.65 & 0.02 & 0.57 \\
\hline \multirow{2}{*}{$\begin{array}{l}14 \\
\text { days }\end{array}$} & Max. & 0.96 & 0.98 & 0.96 & 0.99 & 0.92 & 0.99 & 0.95 & 0.96 & 0.92 & 0.99 & 0.94 & 0.99 & 0.91 & 0.99 & 0.91 & 0.99 \\
\hline & Min. & 0.01 & 0.71 & 0.01 & 0.40 & 0.02 & 0.46 & 0.01 & 0.67 & 0.03 & 0.62 & 0.02 & 0.51 & 0.03 & 0.66 & 0.01 & 0.59 \\
\hline \multirow{2}{*}{$\begin{array}{c}28 \\
\text { days }\end{array}$} & Max. & 0.90 & 0.92 & 0.89 & 0.99 & 0.89 & 0.99 & 0.90 & 0.92 & 0.89 & 0.99 & 0.89 & 0.99 & 0.85 & 0.99 & 0.90 & 0.99 \\
\hline & Min. & 0.02 & 0.67 & 0.02 & 0.45 & 0.02 & 0.48 & 0.02 & 0.67 & 0.02 & 0.45 & 0.02 & 0.48 & 0.02 & 0.68 & 0.01 & 0.59 \\
\hline
\end{tabular}

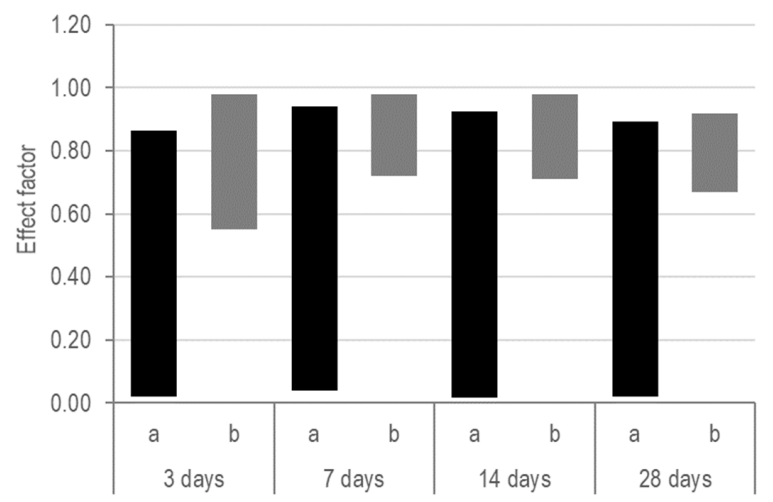

(a)

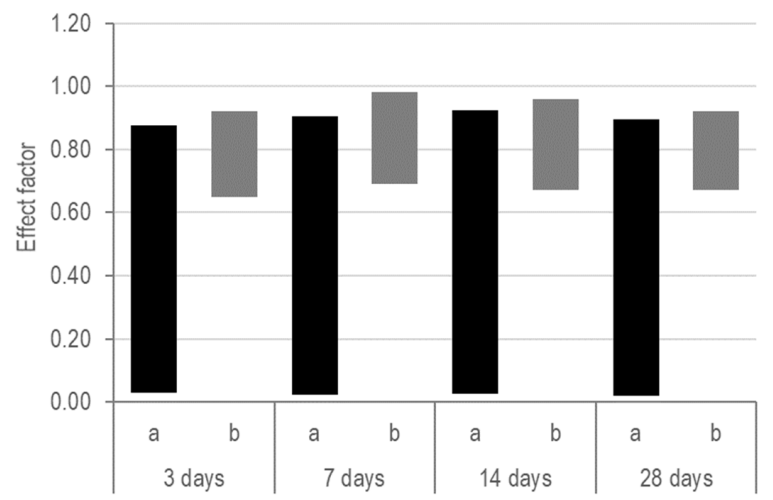

(b)

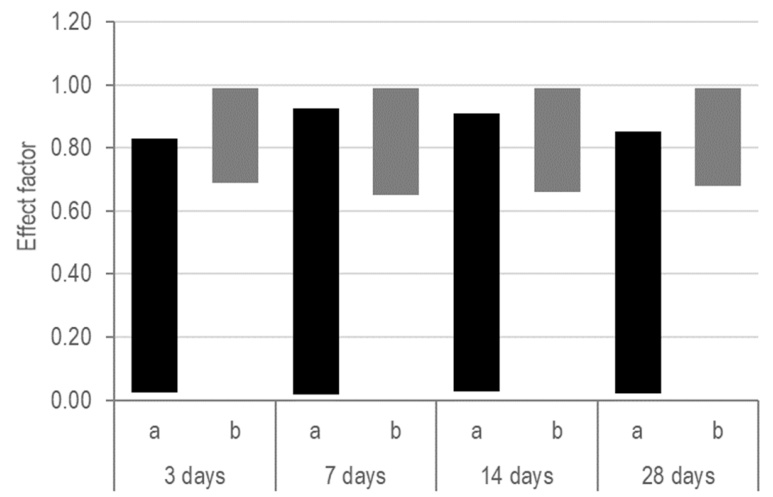

(c)

Figure 10. Common ranges of the effect factors for (a) W170, (b) W160, and (c) W150 mixtures at different ages $(a<b<c, c=1)$. 
For the W170 mixtures, the value of $a$ was in the range of $0.02-0.86$, whereas that of $b$ was $0.55-0.98$ at an age of 3 days. Furthermore, at an age of 7 days, the value of $a$ was in the range of 0.04 to 0.94 , whereas that of $b$ was 0.72 to 0.98 , indicating that the influence of DS and CS on compressive strength was more significant at an age of 7 days than at 3 days. At an age of 14 days, the value of $a$ was in the range of 0.02 to 0.92 , whereas that of $b$ was in the range of 0.71 to 0.98 , which were similar to the ranges at 7 days. Finally, at an age of 28 days, the value of $a$ was in the range of 0.02 to 0.89 , whereas that of $b$ was 0.67 to 0.92 , indicating that the influences of DS and CS on the compressive strength decreased slightly at this age compared with those at 7 and 14 days.

For the W160 mixtures, the value of $a$ was in the range of 0.03 to 0.88 , whereas that of $b$ was 0.65 to 0.92 at an age of 3 days. Furthermore, at an age of 7 days, the value of $a$ was in the range of 0.02 to 0.90 , whereas that of $b$ was 0.69 to 0.98 , indicating that the influence of CS on the compressive strength was more significant than at 3 days. At an age of 14 days, the value of $a$ was in the range of 0.03 to 0.92 , whereas that of $b$ was 0.67 to 0.96 . Finally, at an age of 28 days, the value of $a$ was in the range of 0.02 to 0.89 , whereas that of $b$ was 0.67 to 0.92 .

For the W150 mixtures, the value of $a$ was in the range of 0.03 to 0.83 , whereas that of $b$ was 0.69 to 0.99 at an age of 3 days. Furthermore, at an age of 7 days, the value of $a$ was in the range of 0.02 to 0.93 , whereas that of $b$ was 0.65 to 0.99 , indicating that the influence of DS on the compressive strength was more significant than at 3 days. At an age of 14 days, the value of $a$ was in the range of 0.03 to 0.91 , whereas that of $b$ was 0.66 to 0.99 , which were similar to the ranges at 7 days. Finally, at an age of 28 days, the value of $a$ was in the range of 0.02 to 0.85 , whereas that of $b$ was 0.68 to 0.99 , indicating that the influence of DS on the compressive strength decreased slightly compared with the results at 7 and 14 days.

Based on the obtained values, the common ranges of $a$ and $b$ were obtained for all ages. For the W170 mixtures they were 0.04 to 0.86 and 0.72 to 0.92 , respectively; for the W160 mixtures they were 0.03 to 0.88 and 0.69 to 0.92 , respectively; and for the W150 mixtures they were 0.03 to 0.83 and 0.69 to 0.99 , respectively, indicating that the influence of CS on compressive strength was slightly more significant compared to the other mixtures with different water contents. Overall, for all of the mixtures, the common ranges of $a$ and $b$ were 0.04 to 0.83 and 0.72 to 0.92 , respectively.

\subsubsection{For $0<c<b<a$ and $a=1$}

Table 5 lists the results, with the maximum and minimum values of effect factors $b$ and $c$ that satisfy Equation (1) under the conditions: $0<c<b<a$ and $a=1$. In addition, Figure 11 shows the common ranges of the effect factors of CS and CA for each age.

Table 5. Results of the calculated aggregate effect factors $(a>b>c, a=1)$.

\begin{tabular}{|c|c|c|c|c|c|c|c|c|c|c|c|c|c|c|c|c|c|}
\hline \multirow{3}{*}{ Age } & \multirow{3}{*}{$\begin{array}{c}\text { Mixture } \\
\text { Factor }\end{array}$} & \multicolumn{6}{|c|}{ W170 } & \multicolumn{6}{|c|}{ W160 } & \multicolumn{4}{|c|}{ W150 } \\
\hline & & \multicolumn{2}{|c|}{ D10 } & \multicolumn{2}{|c|}{ D40 } & \multicolumn{2}{|c|}{ D60 } & \multicolumn{2}{|c|}{ D10 } & \multicolumn{2}{|c|}{ D40 } & \multicolumn{2}{|c|}{ D60 } & \multicolumn{2}{|c|}{ D40 } & \multicolumn{2}{|c|}{ D60 } \\
\hline & & $b$ & $c$ & $b$ & $c$ & $b$ & $c$ & $b$ & $c$ & $b$ & $c$ & $b$ & $c$ & $b$ & $c$ & $b$ & $c$ \\
\hline \multirow{2}{*}{$\begin{array}{c}3 \\
\text { days }\end{array}$} & Max. & 0.97 & 0.96 & 0.99 & 0.98 & 0.99 & 0.84 & 0.98 & 0.97 & 0.99 & 0.93 & 0.99 & 0.94 & 0.99 & 0.90 & 0.99 & 0.89 \\
\hline & Min. & 0.44 & 0.01 & 0.62 & 0.01 & 0.61 & 0.01 & 0.32 & 0.02 & 0.45 & 0.01 & 0.55 & 0.02 & 0.44 & 0.01 & 0.51 & 0.02 \\
\hline \multirow{2}{*}{$\begin{array}{c}7 \\
\text { days }\end{array}$} & Max. & 0.96 & 0.95 & 0.99 & 0.91 & 0.99 & 0.92 & 0.96 & 0.95 & 0.99 & 0.93 & 0.99 & 0.94 & 0.99 & 0.96 & 0.99 & 0.96 \\
\hline & Min. & 0.29 & 0.02 & 0.65 & 0.02 & 0.61 & 0.01 & 0.31 & 0.01 & 0.45 & 0.01 & 0.55 & 0.02 & 0.40 & 0.01 & 0.47 & 0.02 \\
\hline \multirow{2}{*}{$\begin{array}{c}14 \\
\text { days }\end{array}$} & Max. & 0.98 & 0.99 & 0.99 & 0.94 & 0.99 & 0.90 & 0.91 & 0.90 & 0.99 & 0.95 & 0.99 & 0.93 & 0.99 & 0.95 & 0.99 & 0.93 \\
\hline & Min. & 0.28 & 0.01 & 0.63 & 0.01 & 0.62 & 0.01 & 0.30 & 0.02 & 0.44 & 0.01 & 0.55 & 0.01 & 0.41 & 0.02 & 0.49 & 0.02 \\
\hline \multirow{2}{*}{$\begin{array}{c}28 \\
\text { days }\end{array}$} & Max. & 0.80 & 0.79 & 0.99 & 0.83 & 0.99 & 0.85 & 0.80 & 0.79 & 0.99 & 0.83 & 0.99 & 0.85 & 0.99 & 0.91 & 0.99 & 0.92 \\
\hline & Min. & 0.24 & 0.01 & 0.68 & 0.02 & 0.64 & 0.01 & 0.24 & 0.01 & 0.68 & 0.02 & 0.64 & 0.01 & 0.43 & 0.01 & 0.49 & 0.01 \\
\hline
\end{tabular}




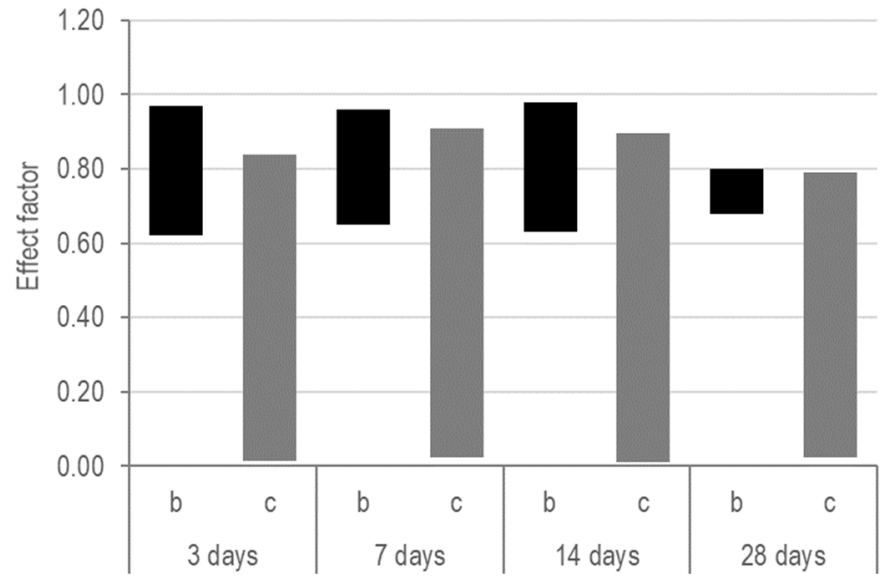

(a)

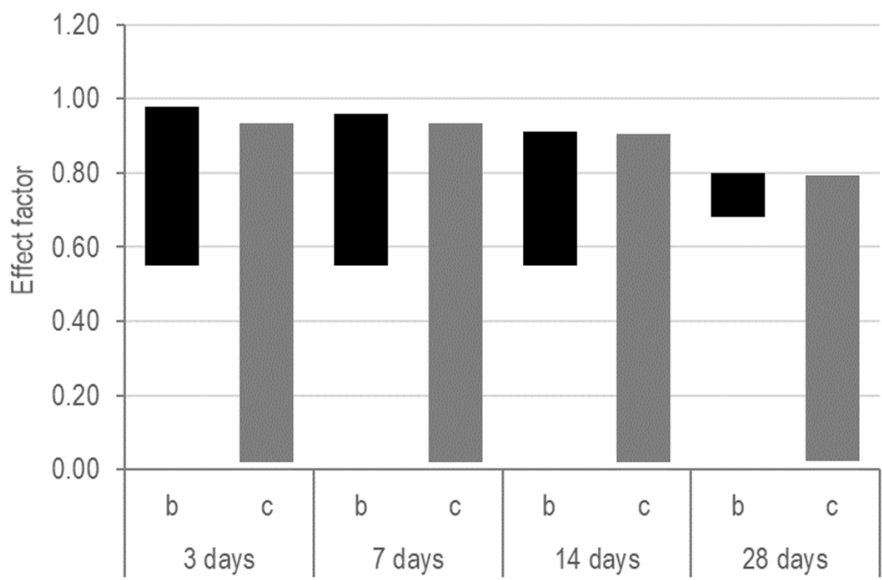

(b)

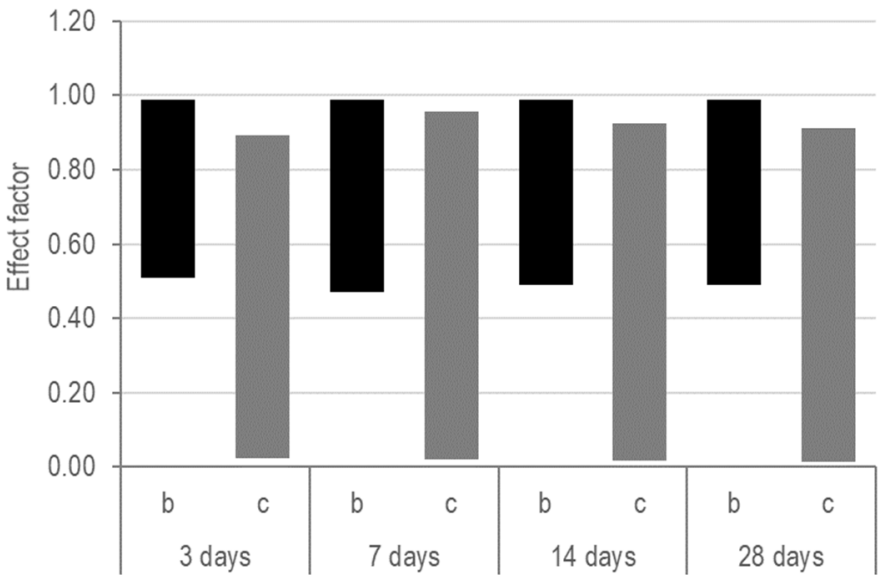

(c)

Figure 11. Common ranges of the effect factors for the (a) W170, (b) W160, and (c) W150 mixtures at different ages $(a>b>c, a=1)$.

The results indicate that the value of $c$ generally increased as the value of $b$ increased. Similarly, the value of $c$ decreased as the value of $b$ decreased; however, the decrease in $c$ was larger than that of $b$. For the W170 mixtures, the value of $b$ was in the range of 0.62 to 0.97, whereas that of $c$ was 0.01 to 0.84 at an age of 3 days. Furthermore, at an age of 7 days, the value of $b$ was in the range of 0.65 to 0.96 , whereas that of $c$ was 0.02 to 0.91 , indicating that the influence of CA on the compressive strength was more significant compared than at 3 days. At an age of 14 days, the value of $b$ was in the range of 0.63 to 0.98 , whereas that 
of $c$ was 0.01 to 0.90 . Finally, at an age of 28 days, the value of $b$ was in the range of 0.68 to 0.80 , whereas that of $c$ was 0.02 to 0.79 , indicating that the influence of CS and CA on the compressive strength at 28 days decreased compared to the other ages.

For the W160 mixtures, the value of $b$ was in the range of 0.55 to 0.98 , whereas that of $c$ was 0.02 to 0.93 at an age of 3 days. Furthermore, at an age of 7 days, the value of $b$ was in the range of 0.55 to 0.96 , whereas that of $c$ was 0.02 to 0.93 . At an age of 14 days, the value of $b$ was in the range of 0.55 to 0.91 , whereas that of $c$ was 0.02 to 0.90 . Finally, at an age of 28 days, the value of $b$ was in the range of 0.68 to 0.80 , whereas that of $c$ was 0.02 to 0.79 , indicating that the influence of CS and CA on the compressive strength at 28 days decreased compared to the other ages.

For the W150 mixtures, the value of $b$ was in the range of 0.51 to 0.99 , whereas that of $c$ was 0.02 to 0.89 at an age of 3 days. Furthermore, at an age of 7 days, the value of $b$ was in the range of 0.47 to 0.99 , whereas that of $c$ was 0.02 to 0.96 , indicating that the influence of CA was slightly more significant than at 3 days. At an age of 14 days, the value of $b$ was in the range of 0.49 to 0.99 , whereas that of $c$ was 0.02 to 0.93 . At 28 days, the value of $b$ was in the range of 0.49 to 0.99 , whereas that of $c$ was 0.01 to 0.91 .

Based on the obtained values, the common ranges for $b$ and $c$ for all ages were obtained. For the W170 mixtures, their common ranges for $b$ and $c$ were 0.68 to 0.80 and 0.02 to 0.79 , respectively. For the W160 mixtures, the common ranges were the same as those of the W170 mixtures. Furthermore, for the W150 mixtures, the common ranges for $b$ and $c$ were 0.51 to 0.99 and 0.02 to 0.79 , respectively, which were larger than those of the W170 and W160 mixtures. Overall, for all mixtures, the common ranges of $b$ and $c$ were 0.68 to 0.80 and 0.02 to 0.79 , respectively.

\section{Conclusions}

In this study, the compressive strength properties of concrete for different unit water contents and DS/FA ratios were evaluated. In addition, the effect of each aggregate on the compressive strength of concrete was quantitatively analyzed based on the measured data. The results can be summarized as follows.

(1) The slump/AD ratio increased as the DS/FA ratio increased up to $40 \%$. In particular, a DS/FA ratio of $40 \%$ was the most favorable condition for concrete workability.

(2) The compressive strength of concrete increased until the DS/FA ratio increased to $20 \%$. Thereafter, the compressive strength decreased as the DS/FA ratio increased. For the same DS/FA ratio, the compressive strength tended to increase slightly as the water content decreased.

(3) The effect of the DS/FA ratio on variations in compressive strength was greater than that of the unit water content on variations in compressive strength. Therefore, in terms of the strength of concrete using DS and CS, we recommend that the DS/FA ratio should be considered more important than the unit water content.

(4) The relationship between the changes in compressive strength and aggregate volume fractions was analyzed, considering the effect factors of each aggregate on the compressive strength under conditions (1) $0<\mathrm{DS}(a)<\mathrm{CS}(b)<\mathrm{CA}(c)$ and $(2) 0<\mathrm{CA}(c)<$ $\mathrm{CS}(b)<\mathrm{DS}(a)$.

(5) For $0<a<b<c$ and $c=1$, the value of $a$ generally increased as $b$ increased. Similarly, the value of $a$ decreased as $b$ decreased; however, the decrease in $a$ was larger than that of $b$. In addition, the common ranges of $a$ and $b$ for all of the mixtures were 0.04 to 0.83 and 0.72 to 0.92 , respectively.

(6) For $0<c<b<a$ and $a=1$, the value of $c$ generally increased as $b$ increased. Similarly, the value of $c$ decreased as $b$ decreased; however, the decrease in $c$ was larger than that of $b$. The common ranges of $b$ and $c$ for all of the mixtures were 0.68 to 0.80 and 0.02 to 0.79 , respectively. 
Author Contributions: Conceptualization, E.L.; methodology, J.N.; validation, J.K., J.Y., and S.P.; formal analysis, E.L. and J.N.; investigation, E.L., J.K., J.Y., and S.P.; data curation, E.L.; writing-original draft preparation, E.L.; writing - review and editing, J.N.; supervision, S.P.; project administration, E.L. All authors have read and agreed to the published version of the manuscript.

Funding: This research received no external funding.

Institutional Review Board Statement: Not applicable.

Informed Consent Statement: Not applicable.

Data Availability Statement: Not applicable.

Conflicts of Interest: The authors declare no conflict of interest.

\section{References}

1. Lee, E.; Kim, Y. Application and Characteristics of Dune Sand Concrete in the Middle East and North Africa. J. Korea Concr. Inst. 2014, 26, 55-63. (In Korean) [CrossRef]

2. Zhang, G.; Song, J.; Yang, J.; Liu, X. Performance of Mortar and Concrete Made with a Fine Aggregate of Desert Sand. Build. Environ. 2006, 41, 1478-1481. [CrossRef]

3. Al-Harthy, A.S.; Halim, M.A.; Taha, R.; Al-Jabri, K.S. The Properties of Concrete Made with Fine Dune Sand. Constr. Build. Mat. 2007, 21, 1803-1808. [CrossRef]

4. Bouziani, T.; Bedrinas, M.; Hadjoudja, M. Effect of Dune Sand on the Properties of Flowing Sand-Concrete. Int. J. Concr. Struct. Mater. 2012, 6, 59-64. [CrossRef]

5. Seif, A.; Sedek, E.S. Performance of Cement Mortar Made with Fine Aggregates of Dune Sand, Kharga Oasis, Western Desert, Egypt: An Experimental Study. Jordan J. Civil Eng. 2013, 7, 270-284.

6. Belhadj, B.; Bederina, M.; Benguettache, K.; Queneudec, M. Effect of the Type of Sand on the Fracture and Mechanical Properties of Sand Concrete. Adv. Conc. Constr. 2014, 2, 13-27. [CrossRef]

7. Khay, S.E.E.; Neji, J.; Loulizi, A. Compacted Sand Concrete in Pavement Construction: An Economical and Environmental Solution. ACI Mater. J. 2010, 107, 195-202. [CrossRef]

8. Rmili, A.; Ouezdou, M.B.; Added, M.; Ghorbel, E. Incorporation of Crushed Sands and Tunisian Desert Sands in the Composition of Self-Compacting Concretes Part II: SCC fresh and Hardened States Characteristics. Int. J. Conc. Struct. Mater. 2009, 3, 11-14. [CrossRef]

9. Luo, F.J.; He, L.; Pan, Z.; Duan, W.H.; Zhao, X.L.; Collins, F. Effect of Very Fine Particles on Workability and Strength of Concrete Made with Dune Sand. Constr. Build. Mater. 2013, 47, 131-137. [CrossRef]

10. Alexander, M.; Mindess, S. Aggregate in Concrete; Taylor and Francis: London, UK, 2005.

11. KS F 2402: Method of Test for Slump of Concrete; Korean Standards Association: Seoul, Korea, 2012.

12. ASTM C143: Standard Test Method for Slump of Hydraulic-Cement Concrete; ASTM International: West Conshohocken, PA, USA, 2009.

13. KS F 2421: Method of Test for Air Content of Fresh Concrete by Pressure Method; Korean Standards Association: Seoul, Korea, 2011.

14. ASTM C231: Standard Test Method for Air Content of Freshly Mixed Concrete by the Pressure Method; ASTM International: West Conshohocken, PA, USA, 2009.

15. KS F 2405: Method for Compressive Strength of Concrete; Korean Standards Association: Seoul, Korea, 2010.

16. ASTM C39: Standard Test Method for Compressive Strength of Cylindrical Concrete Specimens; ASTM International: West Conshohocken, PA, USA, 2009.

17. KS F 2526: Concrete Aggregate; Korean Standards Association: Seoul, Korea, 2012.

18. ASTM C33: Standard Specification for Concrete Aggregates; ASTM International: West Conshohocken, PA, USA, 2013.

19. Mehta, P.K.; Monteiro, P.J.M. Concrete-Microstructure, Properties and Materials, 3rd ed.; McGraw-Hill: New York, NY, USA, 2005.

20. Meddah, M.S.; Zitouni, S.; Belâabes, S. Effect of Content and Particle Size Distribution of Coarse Aggregate on the Compressive Strength of Concrete. Constr. Build. Mat. 2010, 24, 505-512. [CrossRef]

21. Stock, A.F.; Hannantt, D.J.; Williams, R.I.T. The Effect of Aggregate Concentration upon the Strength and Modulus of Elasticity of Concrete. Mag. Concr. Res. 1979, 31, 225-234. [CrossRef]

22. De Larrard, F.; Belloc, A. The Influence of Aggregate on the Compressive Strength of Normal and High-Strength Concrete. Mater. J. 1997, 94, 417-426. [CrossRef]

23. Donza, H.; Cabrera, O.; Irassar, E.F. High-strength Concrete with Different Fine Aggregate. Cem. Concr. Res. 2002, 32, $1755-1761$. [CrossRef]

24. Haque, M.B.; Tuhin, I.A.; Farid, M.S.S. Effect of Aggregate Size Distribution on Concrete Compressive Strength. SUST J. Sci. Technol. 2012, 19, 35-39.

25. Vilane, B.R.T.; Sabelo, N. The Effect of Aggregate Size on the Compressive Strength of Concrete. J. Agric. Sci. Eng. 2016, 2, 66-69.

26. Woode, A.; Amoah, D.K.; Aguba, L.A.; Ballow, P. The Effect of Maximum Coarse Aggregate Size on the Compressive Strength of Concrete Produced in Ghana. Civ. Environ. Res. 2015, 7, 7-12. 
27. Yaqub, M.; Bukhari, I. Effect of Size of Coarse Aggregate on Compressive Strength of High Strength Concrete. In Proceedings of the 31st Conference on Our World in Concrete and Structures, Singapore, Singapore, 16-17 August 2006.

28. Oyewole, O.O.; Arilewola, S.S.; Jimoh, A.A.; Oyejobi, D.O. Effects of Aggregate Sizes on the Physical and Mechanical Properties of Concrete Using Artificial Aggregates. In Proceedings of the 3rd Annual Conference on Civil Engineering, Ilorin, Nigeria, 6-8 July 2011; pp. 21-23.

29. Xie, W.; Jin, Y.; Li, S. Experimental Research on the Influence of Grain Size of Coarse Aggregate on Pebble Concrete Compressive Strength. Appl. Mech. Mater. 2012, 238, 133-137. [CrossRef]

30. Bhikshma, V.; Florence, G.A. Studies on Effect of Maximum Size of Aggregate in Higher Grade Concrete with High Volume Fly Ash. Asian J. Civ. Eng. 2013, 14, 101-109. 